\title{
Globe
}

Revue internationale d'études québécoises

\section{Pierre Anctil et Ira Robinson (dir.), Les communautés juives de Montréal. Histoire et enjeux contemporains, Québec, Septentrion, 2010}

\section{Sherry Simon}

Volume 14, numéro 2, 2011

URI : https://id.erudit.org/iderudit/1008793ar

DOI : https://doi.org/10.7202/1008793ar

Aller au sommaire du numéro

Éditeur(s)

Globe, Revue internationale d'études québécoises

ISSN

1481-5869 (imprimé)

1923-8231 (numérique)

Découvrir la revue

Citer ce compte rendu

Simon, S. (2011). Compte rendu de [Pierre Anctil et Ira Robinson (dir.), Les communautés juives de Montréal. Histoire et enjeux contemporains, Québec, Septentrion, 2010]. Globe, 14(2), 232-234. https://doi.org/10.7202/1008793ar d'utilisation que vous pouvez consulter en ligne.

https://apropos.erudit.org/fr/usagers/politique-dutilisation/ 
identitaires, si l'on excepte le Laurin, un modèle où l'histoire littéraire est enfin envisagée pour elle-même, dans toute sa complexité.

L'œuvre de Cellard est profondément originale. Certes, de nombreux essayistes se sont penchés sur les manuels de Roy, mais beaucoup moins l'ont fait sur les autres auteurs dont elle traite. Et surtout, personne n’a songé à les mettre en perspective pour analyser l'évolution du discours qu'ils tiennent sur l'histoire littéraire canadienne-française, devenue québécoise, tout au long du $\mathrm{XX}^{\mathrm{e}}$ siècle. Cellard dégage avec d'infinies nuances les trois temps de son métarécit, prudence louable si l'on songe à la complexité du sujet et à la difficulté qu'il y a à circonscrire ce que l'on entend par les préoccupations humanistes de l'enseignement littéraire. À terme, on la sent tout de même un peu hésitante face à cet acteur collectivement défini dans les manuels et qui chemine vers l'affermissement de sa subjectivité critique individuelle: oublierait-il trop ses racines et ses anciens référents symboliques? Dans quel but au juste faut-il enseigner l'histoire littéraire du Québec?

Monique Lebrun Université du Québec à Montréal

\section{Pierre Anctil et Ira Robinson (dir.) \\ Les communautés juives de Montréal. Histoire et enjeux contemporains, Québec, Septentrion, 2010.}

Premier ouvrage de synthèse sur la communauté juive de Montréal en langue française, ce volume offre un survol précieux de l'histoire et de l'actualité d'une population en pleine mutation. Très diversifié dans son contenu, écrit dans un langage sobre et élégant, le livre embrasse un grand nombre d'aspects de la vie juive à Montréal depuis la Conquête.

Ce qu'on y apprend? Pour ce qui est des origines des Juifs au Québec: que les Juifs n'étaient pas permis de séjour sous le régime français, que celle qui a essayé de s'y introduire en déguisement masculin (Esther Brandeau) en a été vite expulsée, que les premiers Juifs arrivés sous le régime anglais étaient de tradition sépharade. Plus près de nous, on apprend que Montréal est la ville canadienne où le yiddish continue d'être le plus parlé et où le taux de mariages mixtes est le plus bas. Ces deux dernières données peuvent donner l'image d'un judaïsme montréalais plutôt conservateur, 
situation que l'on explique souvent en rapport à la situation culturelle triangulaire de Montréal qui aurait, pour l'ensemble des communautés immigrantes, créé un plus grand conservatisme quailleurs. Mais les statistiques qui dressent le portrait d'ensemble des Juifs de Montréal doivent être lues avec prudence en raison de la présence importante de la communauté hassidique à Montréal. Les caractéristiques de cette communauté - obédience ultraorthodoxe, natalité très importante, pratique de la langue yiddish - tranchent avec celles de l'ensemble de la population juive. Par ailleurs, cette communauté vit en grande partie à l'écart des autres populations, sinon sur le plan physique (seulement quelques communautés ont choisi un lieu de résidence isolé), du moins sur le plan social. L'un des aspects les plus précieux de l'ouvrage est justement de placer dans son contexte historique la situation toute spéciale des Juifs hassidiques de Montréal - leur arrivée relativement récente (après la Deuxième Guerre mondiale), en grande partie des survivants de l'Holocauste, beaucoup ayant transité par Paris - et de montrer à quel point cette communauté est marginale par rapport aux communautés pleinement intégrées dans la vie montréalaise et québécoise. La présentation systématique de Julien Bauer permet une vue claire des différentes composantes du groupe, leurs origines nationales, leurs lieux d'habitation.

La survivance de la langue yiddish portée par la communauté hassidique présente plusieurs éléments de paradoxe. À Montréal, le yiddish a été une langue de la modernité, langue qui a soutenu un important mouvement littéraire et politique au cours de la première moitié du siècle. De cette modernité, il ne reste plus aujourd'hui beaucoup de traces: des cours plutôt symboliques de yiddish dans les écoles juives à tradition séculière, une programmation très restreinte à la Bibliothèque culturelle juive (et qui ira en diminuant avec le décès d'écrivains phares comme Chava Rosenfarb), les activités du théâtre yiddish sous l'égide de Dora puis de Bryna Wasserman. Par contre, le yiddish parlé par les Juifs hassidiques ne rentre nullement dans le cadre de cette modernité, mais représente des valeurs contraires : la religion plutôt que le sécularisme, l'obédience plutôt que la liberté.

La contribution de Yolande Cohen sur la migration maghrébine et plus largement la communauté sépharade de Montréal est d'une grande importance. Cette communauté est appelée à prendre une place de plus en plus affirmée dans la constellation juive montréalaise. Un mouvement dans ce sens a été amorcé par la création du Centre Aleph, centre d'études juives soutenu par la communauté sépharade. De plus, les écrivains issus de cette communauté se font plus nombreux, ainsi que les livres sur des thèmes juifs en français (honorés par la Bibliothèque publique juive et ses prix Segal). 
L'article de Pierre Anctil sur l'évolution des rapports entre Juifs et Québécois francophones sert de pierre angulaire à l'ensemble, puisqu'il établit le contexte historique des relations parfois difficiles entre les communautés. Anctil aborde les points de conflit et les quelques incidents d'antisémitisme qui ont marqué les relations récentes, souvent en relation avec la haute visibilité des communautés hassidiques d'Outremont. Anctil veut dissocier ces incidents du nationalisme québécois, attribuant le blâme plutôt aux «milieux conservateurs». Il n'est par contre pas certain que cette distinction puisse être établie aussi facilement qu'Anctil semble le suggérer (p. 61).

D'autres articles sur la langue yiddish, sur l'histoire des institutions juives à Montréal, sur les créateurs juifs, sur les femmes, sur la question scolaire, sur la vie syndicale viennent parfaire le portrait substantiel de la communauté juive à Montréal. Cet excellent volume servira de point de référence dans les années à venir et vient s'ajouter à un ensemble de parutions récentes (Denis Vaugeois sur la famille Hart, Chantal Ringuet sur l'histoire du yiddish à Montréal, les nombreuses traductions de Pierre Anctil) qui soulignent l'intérêt grandissant des chercheurs francophones pour l'histoire juive montréalaise.

Sherry Simon

Université Concordia

\section{Jean-Pierre Augustin (dir.) \\ Villes québécoises et renouvellement urbain \\ depuis la Révolution tranquille, Pessac, \\ Maison des Sciences de l'homme d'Aquitaine, 2010.}

Ce collectif réunissant 24 auteurs québécois et bordelais fait écho à un colloque tenu en juin 2008 à l'initiative de l'Association française d'études canadiennes et s'inscrit dans le sillage des réflexions menées depuis une quinzaine d'années au Centre d'études canadiennes interuniversitaires de Bordeaux de la Maison des sciences de l'homme d'Aquitaine. Trois autres volumes, parus respectivement en 1998, 2000 et 2008, avaient traité des lieux culturels, des sites publics et de l'urbanité.

Il y est question, dans une première partie intitulée "Laboratoire économique et gouvernance urbaine", de la spécificité d'un modèle de gouvernance montréalais (Juan-Luis Klein et Diane-Gabrielle Tremblay), du 